\title{
Population-Based Imaging and Radiomics: Rationale and Perspective of the German National Cohort MRI Study
}

\section{Populationsbasierte Bildgebung und Radiomics: Rationale und Perspektiven der NAKO-Studie}

Authors

Affiliations
C. L. Schlett ${ }^{1}$, T. Hendel ${ }^{2}$, S. Weckbach ${ }^{1}$, M. Reiser ${ }^{2}$, H. U. Kauczor ${ }^{1}$, K. Nikolaou ${ }^{3}$, M. Günther ${ }^{4}$, M. Forsting ${ }^{5}$, N. Hosten ${ }^{6}$, H. Völzke ${ }^{7}$, F. Bamberg ${ }^{3}$

Affiliation addresses are listed at the end of the article.

\author{
Key words \\ - German National Cohort \\ - population-based imaging \\ - longitudinal cohort study \\ whole-body magnetic reso- \\ nance imaging \\ - phenotyping \\ - radiomics
}

\section{Abstract}

$\nabla$

The MRI study within the German National Cohort, a large-scale, population-based, longitudinal study in Germany, comprises comprehensive characterization and phenotyping of a total of 30000 participants using 3-Tesla whole-body MR imaging. A multi-centric study design was established together with dedicated core facilities for e.g. managing incidental findings or providing quality assurance. As such, the study represents a unique opportunity to substantially impact imaging-based risk stratification leading to personalized and precision medicine. Supported by the developments in the field of computational science, the newly developing scientific field of radiomics has large potential for the future. In the present article we provide an overview on population-based imaging and Radiomics and conceptualize the rationale and design of the MRI study within the German National Cohort. Key Points:

> Population-based imaging and Radiomics constitute two emerging fields with great oppertunities and challenges for Radiology.

- As part of the MRI-study of the NAKO approximately 30000 subjects will undergo 3 Tesla whole-body MRI.

- MR Imaging data is publicly accessable and will provide important insights into the natural history of disease processes and personalized risk profiles of the general population.

Citation Format:

- Schlett CL, Hendel T, Weckbach S etal. Population-Based Imaging and Radiomics: Rationale and Perspective of the German National Cohort MRI Study. Fortschr Röntgenstr 2016; 188: 652-661

\section{Zusammenfassung \\ $\nabla$}

Die NAKO Studie, eine bundesdeutsche populationsbasierte Längsschnittstudie, umfasst neben anderen Untersuchungen eine umfangreiche Phänotypisierung von insgesamt etwa 30000 Teilnehmern mittels 3 Tesla Ganzkörper-MRT. Hierzu wurde ein multizentrisches Design in Verbindung mit umfangreichen Elementen zur Qualitätssicherung und Algorithmen zum Umgang mit MRT-Zufallsergebnissen etabliert. Damit stellt die Studie eine einzigartige Möglichkeit dar, wesentliche Erkenntnisse im Bereich der bildbasierten Risikostratifizierung zu liefern, was zu einer personalisierten Medizin beiträgt. In Kombination mit den aktuellen Entwicklungen der Computerwissenschaften ergeben sich in dem sich entwickelnden radiologischen Schwerpunkt Radiomics Chancen für die Zukunft. Der vorliegende Artikel gibt einen Überblick über populationsbasierte Bildgebung und Radiomics im Allgemeinen und ordnet in diesen Kontext die Rationale und das Design der MRT-Studie der NAKO ein.

\section{Introduction}

$\checkmark$

A new area of radiology, population-based imaging is gaining importance both clinically, e.g. for screening, and in dedicated scientific cohort studies. A current example represents the German National Cohort Study, a largescale longitudinal study within Germany, which has been recruiting since 2014 and will enroll approximately 200000 participants, roughly 30000 of whom will undergo whole-body MRI [1, 2].

Population-based imaging is characterized above all by its methodical approach in which the radiological modality is indicated and specified not with regard to an individual or an individual concrete clinical request for ima- 
ging, but is rather employed in the sense of an overriding approach relevant for the general public [3]. While routine clinical medicine employs evidence-based use of screening examinations for early detection of diseases such as breast cancer or lung cancer [4], vastly broader goals are pursued in the scientific context. Here, population-based imaging is employed to characterize morphological as well as functional alterations of the human body to thereby reach a deeper understanding of the diseases relevant to the population as well as the associated risk factors and outcomes thereof. The newly coined term, "radiomics", frequently associated with this comprehensive data collection is a combination of the root word "radio" as an abbreviation for radiology or imaging in a broader sense and the suffix “-omics". In biology the suffix "-omics" denotes methods concerned with the collective characterization and quantification of the entirety of individual elements such as biological molecules, structures, functions and/or dynamics of an organism. Examples of this are "genomics" or "proteomics" [5]. As it was the case in genetics several years ago, population-based imaging is faced with the challenge of having to sift through the amount of data for relevant contents.

The MRI study of the German National Cohort attempted to respond to these challenges and thereby establish a new scientific field in Germany. This article presents the fundamentals of population-based imaging and the challenges it poses as well as the scientific potential of radiomics, while discussing in this context the MRI study of the National German Cohort and comparing it with different studies.

\section{Study design and research questions for population- based imaging \\ $\nabla$}

\section{Population-based cohort studies}

Unlike diagnostic feasibility studies in which the diagnostic accuracy of new imaging method is examined among a study population of patients with the aid of a reference standard, population-based imaging concentrates on a cohort of study participants which, following inclusion into the study (through baseline examination), is accompanied over a specific period of time and monitored (through follow-up examinations). As a rule, imaging is used in the baseline study to correlated image-based phenotypic features and remarkable or pathological changes in organs with other clinical parameters (cross-sectional analysis). With the aid of follow-ups, phenotypical features gathered at an earlier point can be correlated with a clinical outcome to thereby determine the prognostic relevance thereof (longitudinal analysis). This allows the examination of not only established findings (such as, for example, a myocardial late gadolinium enhancement [6]), but also new, unestablished image-related changes, which can be summarized in the context of novel "imaging biomarkers" [7]. This process of establishing new, prognostic markers is a fundamental goal of this type of study [5, 8]. Another feature is that these studies generally involve a high number of cases (often $n>1000$ ), thereby ensuring sufficiently large power in order to identify and verify the expected associations [8].

\section{Design of the German National Cohort Study}

The German National Cohort Study constitutes a classic population-based longitudinal observational study [1]. A total of approximately 200000 residents of the Federal Republic of Germany ranging between 20 and 69 years of age (age at the start of the study) will be included in the German National Cohort Study. The study participants are recruited at a total of 18 study centers, which cover primarily urban and industrial regions as well as a few rural regions throughout the whole of Germany ( $\bullet$ Fig. 1 ). Each center will include a minimum of approximately 10000 study participants randomly selected from the registry office. All 200000 study participants have gone through a standardized protocol at the local study centers, which was comprised of interviews, questionnaires and medical examinations. In addition, blood and urine samples are taken and other biomaterials collected. Data collection for the baseline-examination is conducted at two intensity levels (Level 1 and 2). All participants undergo a 2.5-hour examination protocol (Level 1), while a subgroup of 40000 participants receives an expanded protocol (additional 4 hours, Level 2) involving more in-depth examinations and questions [1].

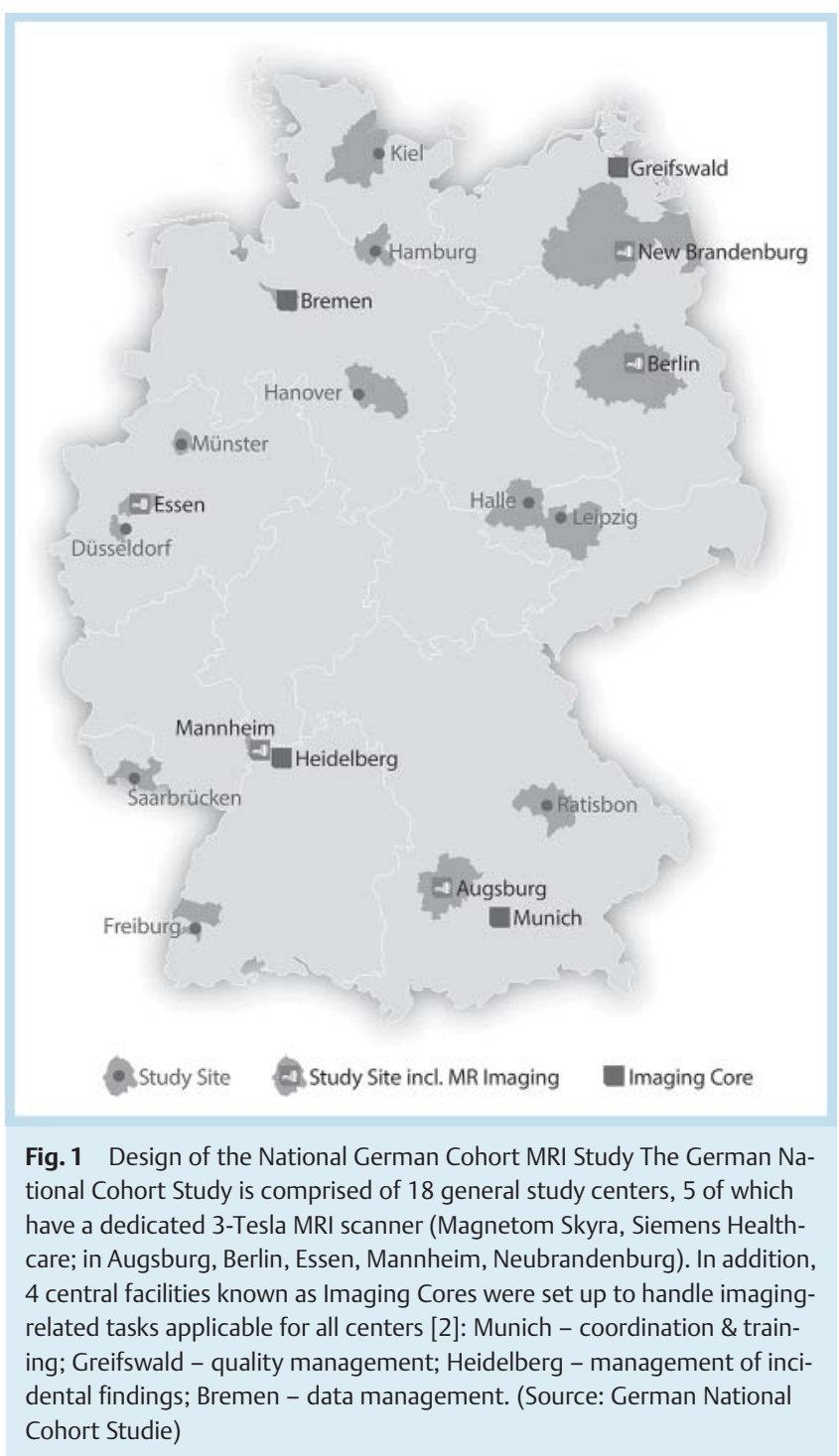


Roughly 30000 participants will additionally be examined with whole-body MRI; therefore 3-Tesla MRI scanners (Magnetom Skyra, Siemens Healthcare, Erlangen) have been installed at five MRI study centers (Augsburg, Berlin, Essen, Mannheim and New Brandenburg: ๑ Fig. 1) [2]. Each of these participants also undergoes the more intense Level 2 examination protocol. So-called imaging cores ( $\bullet$ Fig. 1 ) were established in addition to the MRI study centers. The role of the imaging cores is to provide superordinate coordination and communication as well as the planning, issuing and execution of tasks applicable for all centers [2], which can be divided as follows:

- Imaging core for coordination \& training in Munich

- Imaging core for data management in Bremen

- Imaging core for incidental findings in Heidelberg

- Imaging core for quality management in Greifswald

Following the base-line examination, each study participant is contacted every 2 to 3 years to answer questionnaires concerning lifestyle, risk factors and the appearance of diseases ("active" follow-up) [1]. For "passive" follow-up, established recording systems e.g. the cancer register in cases of newly diagnosed cancers. In the same manner, an effort is made to link the data of the registries and the mandatory health insurance providers to achieve a comprehensive picture of the occurrence of diseases, therapies administered, clinical outcome and mortality.

\section{Research questions posed in the German National Cohort Study}

Consistent with the goals of population-based studies, the German National Cohort Study attains through random sampling a generalizable picture of the overall German population and its relevant widespread diseases. Specifically, it pursues the following four primary goals [1]:

- Clarifying the causes of chronic diseases and presenting the connection with genetic factors as well as lifestyle and environmental influences

- Identifying new risk factors and presenting existing geographic and socioeconomic disparities in terms of health status and disease risk in Germany

- Developing risk-forecasting models for diseases that can be used to derive personalized prevention strategies

- Identifying possibilities for early detection of chronic diseases (evaluation of markers as effective aids for disease prevention)

In this regard, the MRI study within the German National Cohort offers above all great potential for identifying new risk factors and developing personalized prevention strategies [9]. In addition, whole-body MRI offers the unique possibility of linking image-based risk factors with the degree of subclinical disease appearance or with normal variants as well as with classic risk factors and making a correlation with clinical outcome ( 0 Fig. 2 ). This provides a host of possibilities especially when combined with a radiomics approach.

\section{Radiomics}

While the new scientific field radiomics initially emerged from CT-based oncological imaging [10, 11], it is applicable to diverse clinical and scientific areas of imaging regardless of modality $[12,13]$. The object of radiomics is to translate and compile the entirety of the available image-based information of an organism into potentially disease-relevant information. In this process the classic radiological approach centering around an organ-based description of anatomical deviations is taken further, and abstract information based primarily on a quantitative characteristic of image data is compiled on a meta level. Radiomics is based on the hypothesis that similar information, that can be obtained from e.g. serum, genetic or protein analyses, can also be derived from images. In addition, imaging has the advantage of being able to gather information in either a circumscribed or comprehensive manner, while a blood sample, for example, can frequently be taken only on a global level; or biopsies, for example, can again capture only local characteristics of a heterogeneous tumor tissue (e.g., with regard to protein expression). The procedure for developing a radiomics concept follows a set of sequential steps ( 0 Fig. 3):

\section{Standardized imaging in large populations}

To facilitate detection of recurrent pathological changes by means of statistical methods amid the complex variability of the human body, comprehensive image data with a high case number, quality and reproducibility, as is the case in the German National Cohort Study, are fundamental to the approach.

\section{(Semi-) automated segmentation of image files}

Because manual segmentation of image aspects (such as, for example, of certain organs or tumors) would be entail a substantial effort and would be subject to increased variability through differences between multiple readers, complete or partial automatization of image segmentation is essential. While there are several functioning approaches [14, $15]$, this aspect currently poses a challenge for radiomics.

\section{Extraction of image-based features}

Primarily quantitative features such as volumes, intensity, texture, shape or relation to surrounding tissue are abstracted from image data. Moreover, complex, quantitative parameters can also be gathered using new analytical approaches such as, for example, Geographic Object-Based Image Analysis (GEOBIA) [16]. The capturing of image features must accordingly not remain restricted to a clinically indicated request for information.

\section{Analysis of image-based features in association with clinical outcome}

For ascertaining clinical relevance, it is imperative to identify from the plethora of extracted parameters (often several hundred) those features and combinations of features that have an association with the desired clinical outcome (e.g. the prognostic value for cardiac events or genetic expression in tumors [10]). In addition to classic statistical analytical methods, approaches such as, for example, machinebased learning, are also pursued $[14,17]$.

The possibilities of this approach within the actively discussed field of personalized medicine are highly promising. However, they present a major challenge to radiology, particularly with regard to disease prevention [9], given that this concept exceeds the traditional field of radiology and no cor- 


\section{Predictors}

- Genetics

- Physiology

- Environment

- Life-style

- $\quad .$.

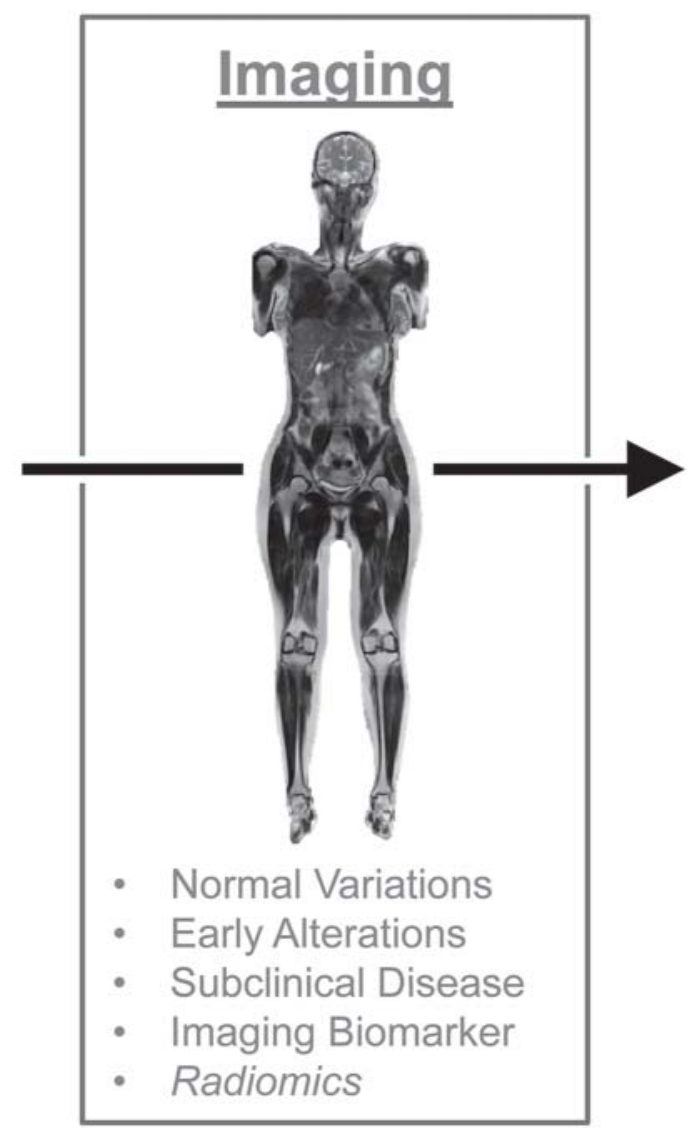

Outcomes

- Cardiovascular

- Oncological

- Neurodegenerative

- ...
Fig. 2 Population-based imaging as a possible means for establishing the unclear connection between modifiable (e. g. lifestyle) and non-modifiable (e. g. genetic) risk factors and clinical outcome. In this process, the quanti- fication of subclinical degrees of disease or imaging biomarkers, for example, is expedient, and concepts such as radiomics are can be applied.

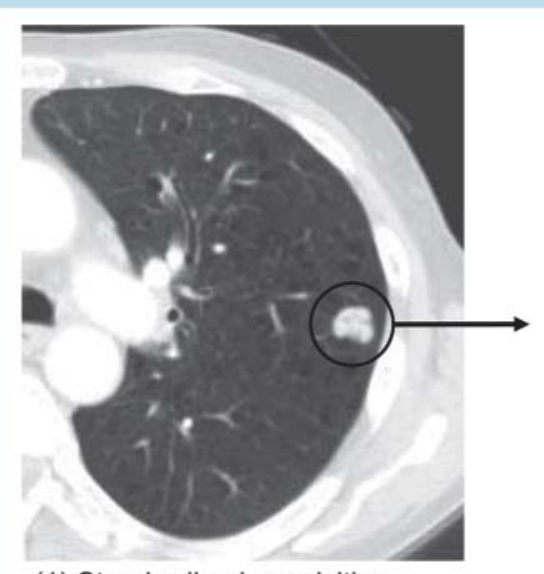

(1) Standardized acquisition

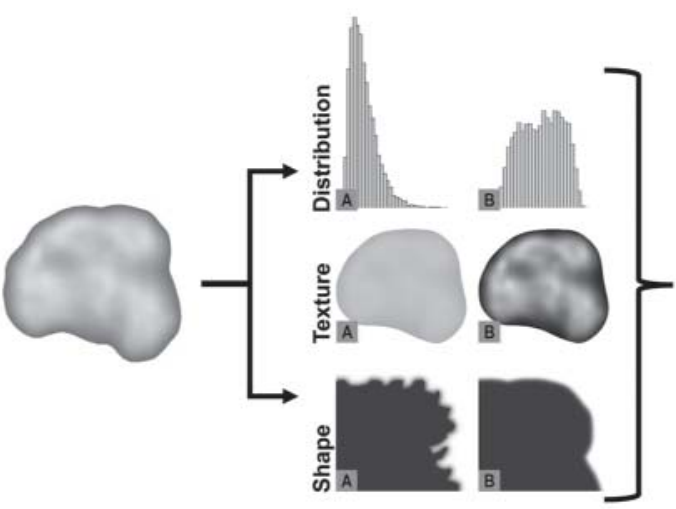

(3) Quant. Image Analysis

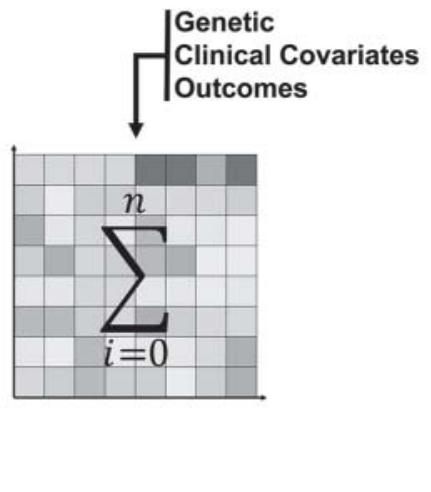

(4) Statistical Analysis

Fig. 3 Schematic process of radiomics using lung cancer as an example. The process covers multiple sequential steps, starting with a standardized image-acquisition in a large population, followed by an automated image segmentation and extraction of image-based features and, finally, an anal-

ysis of image-based features in association with medical data, such as genetics or clinical outcomes. The figure is modified by Aerts et al., Nature Communications 2014 [11]. 
responding scientific and technical resources have been established for this type of data collection and analysis.

\section{Imaging modalities in population-based cohort studies}

The use of modern imaging technology in population-based studies is not new [18], as ultrasound methods have been a regular feature of many population studies for several decades. Clinical imaging modalities such as MRI or computed tomography are playing an increasing role among population-based cohorts. While the choice of modality depends primarily on the research focus, other aspects such as, for example, reproducibility, availability, costs, general legal considerations or risks (e.g. from radiation exposure) play also an important role in the decision.

Ultrasound examination is a relatively cheap easy-to-implement method [19-22] and is thus used frequently ( $\bullet$ Table 1 ), even if the reproducibility of the data and measurement values can at times constitute a limitation [23]. Moreover, the possibilities of a retrospective evaluation of the ultrasound images beyond the primary request for information are limited. The most common area of application of ultrasound in cohort studies is echocardiography [20-22] and examination of the carotids [19-22] ( $\odot$ Table 1 ), e.g. regarding the intima-media thickness, which has established itself as a marker for global arteriosclerosis burden [24]. Within the German National Cohort Study 3D-echocardiography is also part of the Level 2 examination protocol [1].

MRI examination is being used increasingly in populationbased cohort studies, since it achieves a high tissue contrast even without contrast medium and thus has a very low side-effects profile. In particular, cranial MRI examinations performed in previous studies have generated substantial scientific knowledge, such as regarding brain function in the Rotterdam Study or the 3C Study ( $\odot$ Table 1$)[25,26]$. MRI is also frequently used for examining cardiac structures and function [27 -29] as it continues to be the clinical reference standard in this area.

Due to technical enhancements such as parallel acquisition technologies or continuous table feed as well as high magnetic field strengths allow nowadays comprehensive coverage of the entire body within examination times appropriate for study participants [30]. Accordingly, few studies have incorporated whole-body MRI examinations into the study design ( $($ Table 1 ). In addition to the German National Cohort Study, current studies using whole-body MRI protocols would be the Study of Health in Pomerania (SHIP) [31] as well as to a some extent the UK Biobank [32] and the Cooperative Health Research in the Augsburg Region [Kooperative Gesundheitsforschung in der Region Augsburg] (KORA) [29].

The MRI protocol of the German National Cohort Study is comprised of 12 MRI sequences, which can be divided into the focus areas of neurological, cardiovascular, thoracoabdominal and musculoskeletal examination ( $\bullet$ Table 2 ). Each of the focus areas involves an examination time of approximately 15 minutes, yielding a total MRI examination time of 60 minutes (๑ Fig. 4 ).

Because the reproducibility and comparability of the MRI data depend to a certain degree on the selected sequence parameters [33] significant efforts were made in advance to harmonize with other large population-based cohort studies having the same/common sequences ( 0 Table 3 ), even if each study had its own unique sequences. In the Ger-

Table 1 Imaging modalities in population-based cohorts in Europe with existing cohort studies cited as examples.

\begin{tabular}{|c|c|c|c|c|}
\hline & ultrasound & CT & DEXA & MRI \\
\hline costs & + & ++ & + & +++ \\
\hline undesirable effects & none known & radiation exposure ++ & radiation exposure $(+)$ & none known. \\
\hline $\begin{array}{l}\text { possible exclusion } \\
\text { criteria }\end{array}$ & none & $\begin{array}{l}\text { BRCA-mutation, claustro- } \\
\text { phobia, pregnancy }\end{array}$ & pregnancy & $\begin{array}{l}\text { implants not compatible } \\
\text { with MRI, claustrophobia, } \\
\text { pregnancy }\end{array}$ \\
\hline reproducibility & + & +++ & +++ & +++ \\
\hline $\begin{array}{l}\text { whole-body } \\
\text { examinations }\end{array}$ & no & yes & yes & yes \\
\hline mobile solutions & yes & limited & limited & limited \\
\hline $\begin{array}{l}\text { current implementa- } \\
\text { tion (examples, EU } \\
\text { only, sorted by } n \text { ) }\end{array}$ & $\begin{array}{l}\text { - Cardiovascular Risk in } \\
\text { Young Finns Study } \\
\text { ( } \mathrm{n} \approx 1800 . \text { carotids) [19] } \\
\text { - SHIP ( } \approx \approx 2400 \text {. carotids, } \\
\text { liver, thyroid gland, } \\
\text { heart) [20] } \\
\text { - Heinz Nixdorf Recall } \\
\text { ( } \mathrm{n}=8700 . \text { at risk carotids, } \\
\text { heart, pancreas, endo- } \\
\text { thelial dysfunction) [21] } \\
\text { - Rotterdam Study } \\
\text { ( } \mathrm{n} \approx 15000 . \text { carotids, } \\
\text { heart, cerebral vessels, } \\
\text { liver) [22] }\end{array}$ & 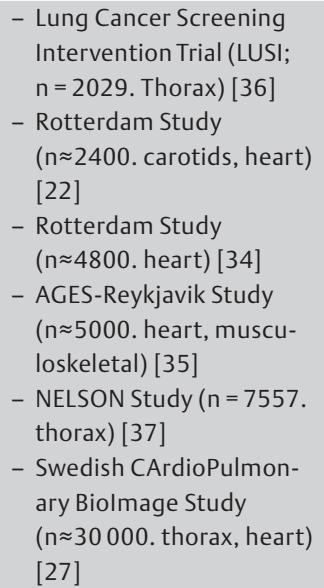 & $\begin{array}{l}\text { - Tromso Study ( } \approx \approx 5000 . \\
\text { hip, spinal column) [39] } \\
\text { - Rotterdam Study } \\
\text { ( } n \approx 15000 . \text { hip) }[22]\end{array}$ & $\begin{array}{l}\text { - KORA-study ( } n=400 . \\
\text { whole body without } \\
\text { musculoskeletal) [29] } \\
\text { - SHIP }(n=3300 . \text { whole } \\
\text { body) [42] } \\
\text { - } 3 \text { C Study ( } n=3300 . \\
\text { cranial) [25] } \\
\text { - SMART Study ( } n=6000 . \\
\text { heart) [28] } \\
\text { - Rotterdam Study } \\
\text { ( } \approx \approx 15000 . \text { cranial, } \\
\text { carotids, knee) [26] } \\
\text { - Swedish CArdioPulmon- } \\
\text { ary Biolmage Study } \\
\text { ( } n \approx 30000 . \text { carotids) [27] }\end{array}$ \\
\hline
\end{tabular}


Table 2 German National Cohort Study whole-body MRI protocol Modified by Bamberg et al. [2].

\begin{tabular}{|c|c|c|c|}
\hline & MR sequence & imaging parameters & anatomical coverage \\
\hline \multirow[t]{3}{*}{$\begin{array}{l}\text { neurological ima- } \\
\text { ging }\end{array}$} & T1w 3 D MPRAGE & $\begin{array}{l}1.0 \times 1.0 \times 1.0 \mathrm{~mm}^{3} \text { (isotropic) voxel size, } \\
\text { sagittal acquisition }\end{array}$ & neurocranium including upper spinal canal \\
\hline & 2 D FLAIR & $0.9 \times 0.9 \times 4.0 \mathrm{~mm}^{3}$ voxel size, axial acquisition & neurocranium \\
\hline & resting-state EPI BOLD & $\begin{array}{l}3.0 \times 1.0 \times 1.0 \mathrm{~mm}^{3} \text { (isotropic) voxel size, axial } \\
\text { acquisition }\end{array}$ & neurocranium \\
\hline \multirow[t]{4}{*}{$\begin{array}{l}\text { cardiovascluar } \\
\text { imaging }\end{array}$} & $\begin{array}{l}\text { MR-angiography 3D } \\
\text { SPACE STIR }\end{array}$ & $1.9 \times 0.9 \times 4.0 \mathrm{~mm}^{3}$ voxel size, coronal acquisition & entire thorax \\
\hline & cine SSFP LAX & $1.5 \times 1.5 \times 6.0 \mathrm{~mm}^{3}$ voxel size & two, three, and four-chamber view \\
\hline & cine SSFP SAX & $1.5 \times 1.5 \times 6.0 \mathrm{~mm}^{3}$ voxel size & 12 short axis slices from base to apex of heart \\
\hline & MOLLISAX & $1.4 \times 1.4 \times 8.0 \mathrm{~mm}^{3}$ voxel size & single short axis slice central-ventricular \\
\hline \multirow{3}{*}{$\begin{array}{l}\text { thoracic-abdo- } \\
\text { minal imaging }\end{array}$} & T2W HASTE & $1.4 \times 1.4 \times 5.0 \mathrm{~mm}^{3}$ voxel size, axial acquisition & shoulders to beneath the kidneys \\
\hline & T1w 3 D VIBE 2-point Dixon & $\begin{array}{l}1.4 \times 1.4 \times 3.0 \mathrm{~mm}^{3} \text { voxel size, axial acquisition, } \\
\text { CAIPIRINHA }\end{array}$ & shoulders to beneath the minor trochanter \\
\hline & multi-echo 3 D VIBE & $\begin{array}{l}1.6 \times 1.6 \times 4.0 \mathrm{~mm}^{3} \text { voxel size, axial acquisition, } \\
6 \text { echoes }\end{array}$ & epigastrium \\
\hline \multirow[t]{2}{*}{$\begin{array}{l}\text { musculoskeletal } \\
\text { imaging }\end{array}$} & PD-fs 3 D SPACE & $\begin{array}{l}1.0 \times 1.0 \times 1.0 \mathrm{~mm}^{3} \text { (isotropic) voxel size, coronal } \\
\text { acquisition }\end{array}$ & $\begin{array}{l}\text { pelvis including the sacroiliac joint and } \\
\text { both hips }\end{array}$ \\
\hline & T2w 2 D Fast Spin-echo & $0.9 \times 0.9 \times 3.0 \mathrm{~mm}^{3}$ voxel size, sagittal acquisition & cervical, thoracic and lumbar spinal column \\
\hline
\end{tabular}
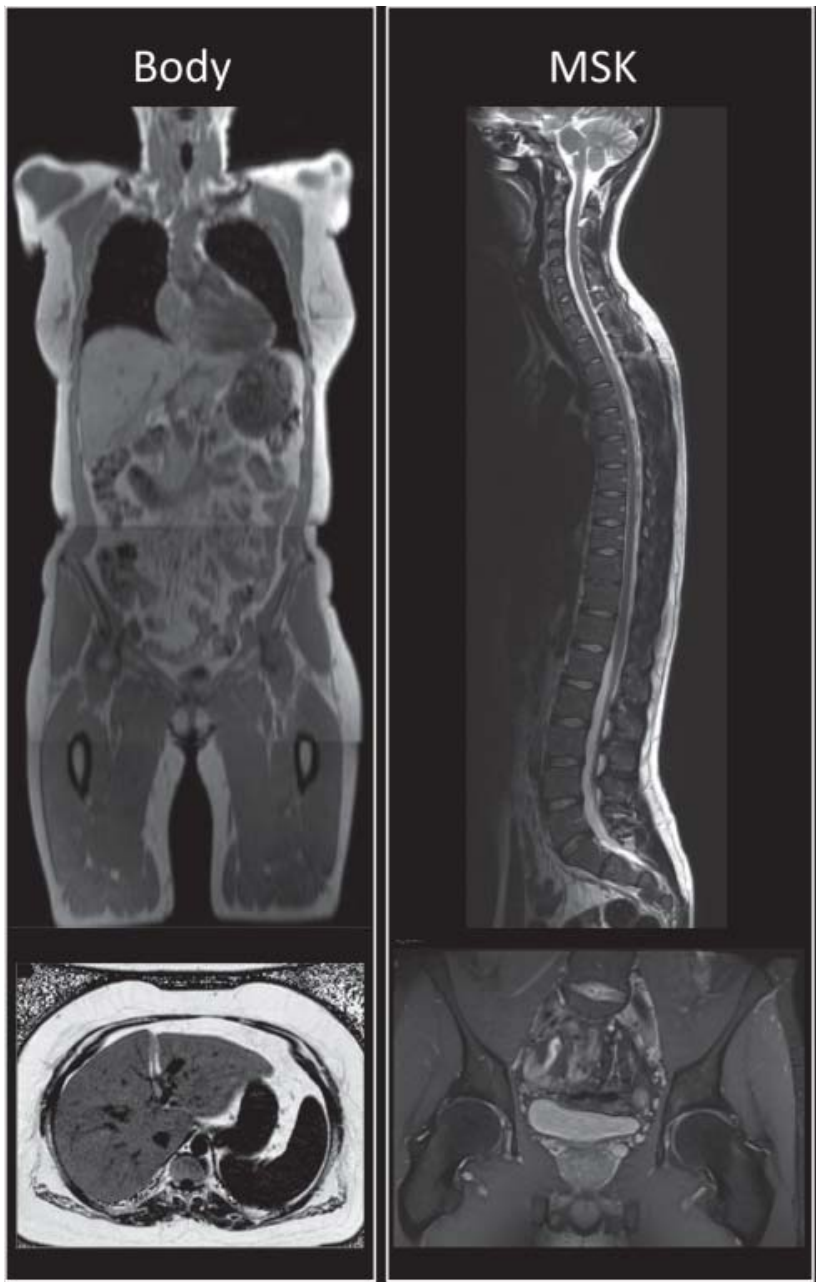

Fig. 4 Examples of the German National Cohort Study divided into 4 research foci: Body with a T1w-GRE, 2-point DIXON of the entire torso, a multi-echo VIBE of the upper abdomen and a T2w-HASTE of the thorax and upper abdomen (no example shown); musculoskeletal system with a T2w-
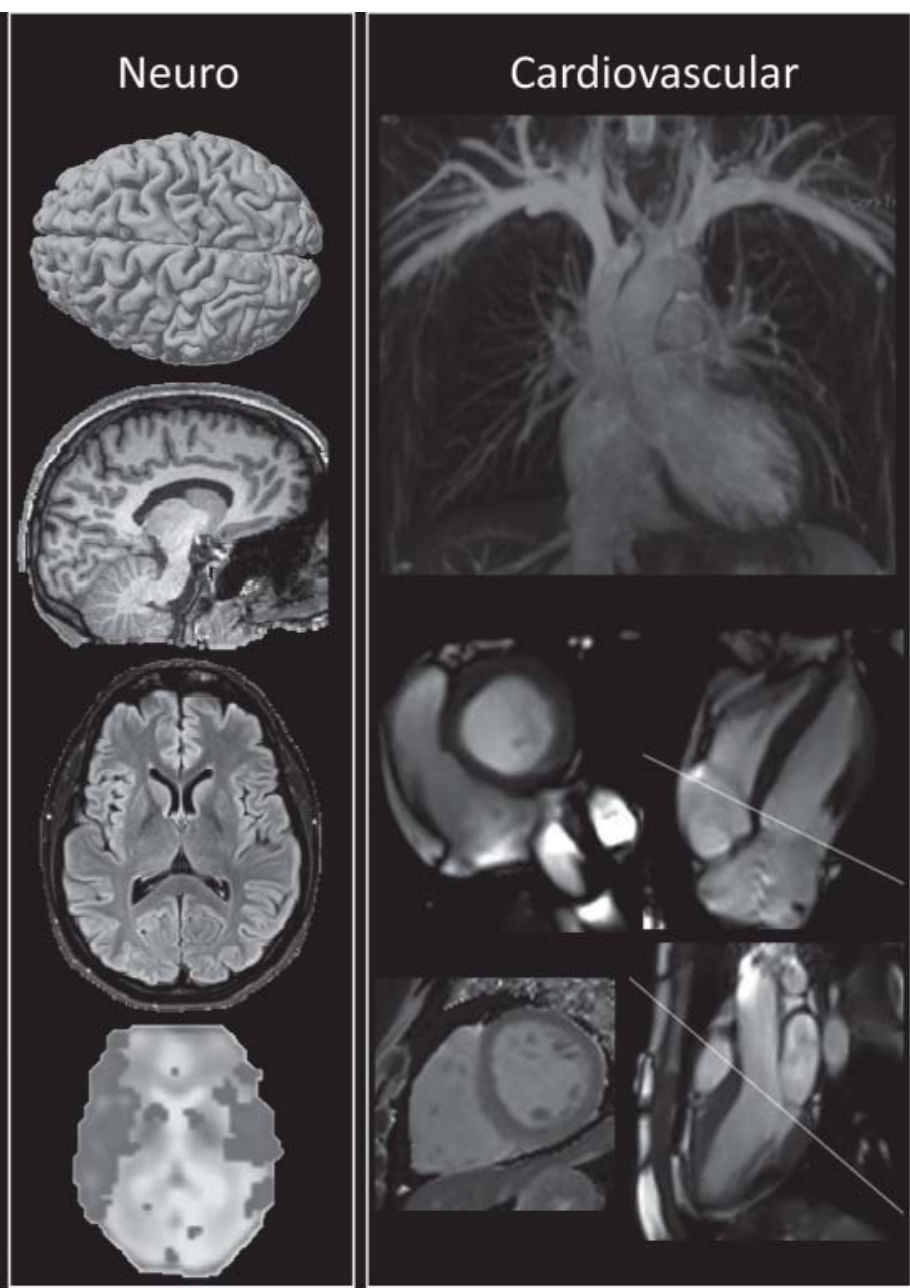

TSE of the spinal column and a PD-fatsat of the pelvis, neurological system with a T1w and FLAIR of the neurocranium as well as a resting state; cardiovascular system with a non-contrast angiogram of the thorax, long- and short-axis CINE of the heart as well as T1-mapping. 
Table 3 MRI protocol comparison between the German National Cohort Study (NAKO) and other population-based cohort studies using MRI.

\begin{tabular}{|c|c|c|c|c|c|}
\hline \multicolumn{2}{|c|}{$\begin{array}{l}\text { German National Cohort } \\
\text { (NAKO) } \\
\text { (3 Tesla) }\end{array}$} & \multirow{2}{*}{$\begin{array}{l}\text { UK Biobank }{ }^{1} \\
\text { (3 Tesla \& } 1.5 \text { Tesla) } \\
\text { comparable }\end{array}$} & \multirow{2}{*}{$\begin{array}{l}\text { SHIP } \\
\text { (1.5 Tesla) } \\
\text { comparable (axial vs. sagittal } \\
\text { in the NAKO) }\end{array}$} & \multirow{2}{*}{$\begin{array}{l}\text { Rotterdam Scan Study }{ }^{2} \\
\text { (1.5 Tesla) } \\
\text { slice thickness ( } 0.8 \mathrm{~mm} \text { vs. } \\
1.0 \mathrm{~mm} \text { in the NAKO) }\end{array}$} & \multirow{2}{*}{$\begin{array}{l}\text { KORA } \\
\text { ( } 3 \text { Tesla) } \\
\text { voxel size }\left(0.3 \times 0.3 \times 0.3 \mathrm{~mm}^{3}\right. \\
\text { vs. } 1.0 \times 1.0 \times 1.0 \mathrm{~m}^{3} \text { in the } \\
\text { NAKO) }\end{array}$} \\
\hline $\begin{array}{l}\text { neurological } \\
\text { imaging }\end{array}$ & $\begin{array}{l}\text { T1w } 3 \text { D } \\
\text { MPRAGE }\end{array}$ & & & & \\
\hline & 2 D FLAIR & $\begin{array}{l}\text { voxel size } \\
\left(1.0 \times 1.0 \times 1.1 \mathrm{~mm}^{3} \text { vs. } 0.9 \times\right. \\
\left.0.9 \times 4.0 \mathrm{~m}^{3} \text { in the NAKO }\right)\end{array}$ & $\begin{array}{l}\text { slice thickness ( } 3 \mathrm{~mm} \text { vs. } \\
4 \mathrm{~mm} \text { in the NAKO) }\end{array}$ & $\begin{array}{l}\text { slice thickness }(2.5 \mathrm{~mm} \text { vs. } \\
4.0 \mathrm{~m} \text { min the NAKO) }\end{array}$ & $\begin{array}{l}\text { voxel size }\left(0.5 \times 0.5 \times 0.9 \mathrm{~mm}^{3}\right. \\
\text { vs. } 0.9 \times 0.9 \times 4.0 \mathrm{~mm}^{3} \text { in the } \\
\text { NAKO })\end{array}$ \\
\hline & $\begin{array}{l}\text { resting-state } \\
\text { EPI BOLD }\end{array}$ & $\begin{array}{l}\text { voxel size } \\
\left(2.4 \times 2.4 \times 2.4 \mathrm{~mm}^{3} \text { vs. }\right. \\
3.1 \times 3.1 \times 3.1 \mathrm{~mm}^{3} \text { in the } \\
\text { NAKO }) \text {; measurement time } \\
\text { comparable; TR }(0.735 \mathrm{~s} \\
\text { vs. } 2.2 \mathrm{~s} \text { in the NAKO); } \\
\text { Multiband } \\
(8 \times \text { vs. none in the NAKO) }\end{array}$ & N/A & $\begin{array}{l}\text { slice thickness ( } 3.5 \mathrm{~mm} \text { vs. } \\
\text { NAKO } 3.1 \mathrm{~mm} \text { ); measure- } \\
\text { ment time ( } 7.73 \text { min vs. } \\
\text { NAKO } 6 \mathrm{~min}) \text {; TR ( } 2.9 \mathrm{~s} \text { vs. } \\
\text { NAKO } 2.2 \mathrm{~s} \text { ) }\end{array}$ & $\mathrm{N} / \mathrm{A}$ \\
\hline \multirow[t]{3}{*}{$\begin{array}{l}\text { cardiac } \\
\text { imaging }\end{array}$} & CINE LAX/SAX & $\begin{array}{l}\text { Voxel size }(1.8 \times 1.8 \times 6.0 / \\
8.0 \mathrm{~mm}^{3} \text { vs. } 1.5 \times 1.5 \times \\
\left.6.0 \mathrm{~mm}^{3} \text { in the NAKO }\right)\end{array}$ & $\begin{array}{l}\text { voxel size }(2.2 \times 1.8 \times 6.0 / \\
7.0 \mathrm{~mm}^{3} \text { vs. } 1.5 \times 1.5 \times \\
\left.6.0 \mathrm{~mm}^{3} \text { in the NAKO }\right)\end{array}$ & $\mathrm{N} / \mathrm{A}$ & $\begin{array}{l}\text { slice thickness ( } 8.0 \mathrm{~mm} \text { vs. } \\
6.0 \mathrm{~mm} \text { in the NAKO) }\end{array}$ \\
\hline & T1-mapping & $\begin{array}{l}\text { sequence (shMOLLI vs. } \\
\text { MOLLI in the NAKO) }\end{array}$ & $\mathrm{N} / \mathrm{A}$ & $\mathrm{N} / \mathrm{A}$ & $\begin{array}{l}\text { voxel size }\left(1.5 \times 1.5 \times 8.0 \mathrm{~mm}^{3}\right. \\
\text { vs. } 1.4 \times 1.4 \times 8.0 \mathrm{~mm}^{3} \text { in the } \\
\text { NAKO })\end{array}$ \\
\hline & $\begin{array}{l}3 \text { D MR- angio- } \\
\text { graphy }\end{array}$ & N/A & $\begin{array}{l}\text { contrast (with vs. without } \\
\text { contrast medium in the NAKO) }\end{array}$ & $\mathrm{N} / \mathrm{A}$ & $\mathrm{N} / \mathrm{A}$ \\
\hline \multirow[t]{3}{*}{$\begin{array}{l}\text { thoracic- } \\
\text { abdominal } \\
\text { imaging }\end{array}$} & T1w-3D-GRE & comparable & $\begin{array}{l}\text { voxel size }\left(1.8 \times 1.8 \times 3.0 \mathrm{~mm}^{3}\right. \\
\text { vs. } 1.4 \times 1.4 \times 3.0 \mathrm{~mm}^{3} \text { in the } \\
\text { NAKO })\end{array}$ & $\mathrm{N} / \mathrm{A}$ & $\begin{array}{l}\text { voxel size }\left(1.7 \times 1.7 \times 1.7 \mathrm{~mm}^{3}\right. \\
\text { vs. } 1.4 \times 1.4 \times 3.0 \mathrm{~mm}^{3} \text { in the } \\
\text { NAKO })\end{array}$ \\
\hline & T2w-HASTE & $\mathrm{N} / \mathrm{A}$ & $\begin{array}{l}\text { voxel size }\left(2.3 \times 1.8 \times 5.0 \mathrm{~mm}^{3}\right. \\
\text { vs. } 1.4 \times 1.4 \times 5.0 \mathrm{~mm}^{3} \text { in the } \\
\text { NAKO })\end{array}$ & $\mathrm{N} / \mathrm{A}$ & $\begin{array}{l}\text { voxel size }\left(1.2 \times 1.2 \times 5.0 \mathrm{~mm}^{3}\right. \\
\text { vs. } 1.4 \times 1.4 \times 5.0 \mathrm{~mm}^{3} \text { in the } \\
\text { NAKO })\end{array}$ \\
\hline & multi-echo $3 \mathrm{D}$ & $\begin{array}{l}\text { anatomical coverage } \\
\text { (single-slice vs. entire liver } \\
\text { in the NAKO) } \\
\text { Number of echoes } \\
\text { ( } 1 \text { - } 8 \text { vs. } 6 \text { in the NAKO) }\end{array}$ & $N / A$ & $\mathrm{~N} / \mathrm{A}$ & $\begin{array}{l}\text { voxel size }\left(1.8 \times 1.8 \times 4.0 \mathrm{~mm}^{3}\right. \\
\text { vs. } 1.6 \times 1.6 \times 4.0 \mathrm{~mm}^{3} \text { in the } \\
\text { NAKO) }\end{array}$ \\
\hline musculoske- & 3 D PD-fs Hip & $\mathrm{N} / \mathrm{A}$ & $\mathrm{N} / \mathrm{A}$ & $\mathrm{N} / \mathrm{A}$ & $\mathrm{N} / \mathrm{A}$ \\
\hline letal imaging & T2w Spine & $\mathrm{N} / \mathrm{A}$ & $\begin{array}{l}\text { voxel size }\left(1.1 \times 1.1 \times 4.0 \mathrm{~mm}^{3}\right. \\
\text { vs. } 0.9 \times 0.9 \times 3.0 \mathrm{~mm}^{3} \text { in the } \\
\text { NAKO })\end{array}$ & N/A & N/A \\
\hline
\end{tabular}

N/A (not acquired) denotes sequences used in the NAKO but not in the other study.

${ }^{1}$ Compared with the MRI protocol of the pilot study of the UK Biobank (N $\approx 5000$ test subjects). UK Biobank uses a 3 Tesla MRI-scanner for neuro imaging and a 1.5 Tesla MRI scanner for all other imaging.

${ }^{2}$ For the Rotterdam Scan Study only slice thicknesses without X/Y-resolution are published [26]. "N/A" denotes "not acquired" in the corresponding study.

man National Cohort Study, specifically the non-contrast thoracic MR-angiography, the T1-mapping of the left ventricle, but also the multi-echo sequences of the upper abdomen and the high-resolution 3D-PD-fs sequence of the pelvis were innovative approaches that set themselves apart from the MRI examination of other studies ( $\bullet$ Table 3 ).

The use of $x$-ray-based modalities is also thoroughly established in population-based studies, but is used clearly more restrictively on "healthy" subjects given the ionizing potential. Examples would be non-contrast cardiac CTs in the Heinz-Nixdorf Recall Study, the Rotterdam Study, the AGESReykjavik Study or the Swedish CardioPulmonary BioImage Study for quantifying coronary calcification $[22,27,34,35]$. Another example would be the use of low-dose CT for lung cancer screening $[36,37]$. The use of $x$-rays must always be assessed in relation to the scientific and social benefits, and the implicit risk must be justified. Dual energy $\mathrm{x}$-ray absorptiometry (DEXA) uses clearly less $\mathrm{x}$-ray radiation $(<10 \mu \mathrm{Sv})$
[38]. Whole-body DEXA allows cost-effective and simple quantification of bone density as it did, for example, in the Tromoso Study or the Rotterdam Study [22, 39]. Moreover, DEXA allows a quantification of fat and fat-free mass [40], yet no separation of local fat deposits (e.g. visceral fat) as is possible with CT or MRI. DEXA therefore supplements rather than replaces other modalities. In this context whole-body DEXA examination is used, for example in the UK Biobank [41].

\section{Challenges of population-based imaging}

$\nabla$

As with other extensive population-based studies, the German National Cohort MRI Study faces multiple major challenges in generating an optimally comprehensive dataset while using a high-resolution imaging modality. Added to this are the high degree of necessary quality assurance, a 
complex management structure and the evaluation of enormous amounts of data and, in terms of ethical considerations, handling incidental findings.

\section{Incidental findings in population-based imaging}

Because of the comprehensive, high-resolution MRI data, the prevalence of relevant incidental findings is not insignificant even among asymptomatic study participants [42]. However, dealing with these "incidental findings", as they are called, in the study setting of the National German Cohort without knowledge of the participants' medical histories or clinical symptoms is highly complex. Communicating the incidental findings may facilitate curative treatment of the diseases (e.g. early detection of lung cancer). On the other hand communication constitutes intervention in the natural course of the disease and influences the observed and scientific findings gained through the study. This is especially relevant for the population-based longitudinal study in which the observation of potentially "normal", disease processes is often one of the declared goals in order to observe the connection between exposure and disease occurrence in a manner with as little influence as possible. The theoretical option of not informing the study participants of these incidental findings has been rejected so far by most ethics committees in the context of populationbased imaging in Germany and is not in the personal interest of many study participants [43]. Further it is nearly impossible to provide always final diagnosis for the incidental findings particularly because the MRI protocol is often not designed to detect a specific disease, but rather to provide a morphological or functional phenotyping. Non-definitive reports generally prompt additional tests, which in turn may entail certain risks, side-effects and expenses.

In the German National Cohort MRI Study all acquired images are reviewed by a board certified radiologist for the presence of incidental findings. A list of incidental findings was developed in advance jointly with radiologists, various clinical disciplines, ethicists and epidemiologists that classifies incidental findings as "notification urgently required", "notification required" and "notification not required". Criteria for the need to notify are (1) clinical consequence of the incidental finding, (2) negative ramifications for the participant if not notified and (3) optimally low false-positive rate of the MRI report for the assumed disease. This list is continuously updated based on new research findings and recommendations of the clinical associations, and can be viewed online (www.national-kohorte.de).

\section{Quality management}

With population-based imaging, special challenges arise due to the large size of the studies, with test subjects frequently numbering many thousands, and, as the case may be, the multicentric design. To also detect faint associations between imaging and clinical variables (e.g. outcomes, genetics, serum biomarkers), it is necessary to reduce errors and variability in image acquisition to a technologically feasible minimum. Without consistent homogeneity of data, both among the study centers and over the course of time, investigations with regard to geographical disparities, for example, are possible only to a limited extent. Accordingly, the following quality management measures were established in the German National Cohort Study [2]:

\section{Defining quality standard}

Quality standards coordinated across interdisciplinary lines were documented in "Standard-Operating-Procedures" (SOP) and communicated to all employees through a training and certification process.

\section{Checking against the quality standard}

All acquired data are automatically checked for completeness (e.g. "all sequences examined?", “sequences repeated?") and correctness (sequence parameters, number of slices, etc.). Moreover, image quality parameters are gathered automatically, such as signal-to-noise-ratio (SNR) or ghosting-level [2]. For additional monitoring, MRI phantoms undergo measurement and automated quantitative evaluation on a weekly basis. The visual quality of images are also evaluated at the study center by the local radiologists. Quality assurance likewise includes an independent evaluation of a $10 \%$ random sampling at the imaging core in Greifswald (over-reading).

\section{Measures for deviations from quality standard}

All parameters recorded in the process of quality assurance are presented in a quality report with dynamic threshold values. When the threshold is exceeded, the study center is notified, which then enacts centrally initiated measures such as, for example, retraining or study center visits if a correction has not been made.

\section{Data management and evaluation}

Current projections alone place the size of the baseline MRI data in the National German Cohort study at over 90 terabytes, which, for security regulations, are stored long-term at two spatially separated locations $[1,44]$. To facilitate rapid access to data, an upload approver were established in the German National Cohort Study, which allows. This model was realized as a web-based platform that facilitates decentral processing in an internet browser without local software installation. For the long term, scientific evaluation shall follow the same procedure, with scientists gaining access to the MRI data via a web-based platform on which the various evaluation tools are implemented and individual measurement algorithms can be introduced via appropriate interfaces. In addition to the automatization of these algorithms, this infrastructure allows rapid, decentralized, multicentric evaluation and thereby maximum usability of the acquired MRI data while at the same time providing quality control [44].

\section{Public access and future developments \\ $\nabla$}

According to the statutes of the Nationale Kohorte e. V. [Association of the German National Cohorts Study], the generated data are available both to the national and international scientific community. This results in a usage right extending beyond the initially involved institutions with far-reaching scientific potential. For radiology, the German National Cohort MRI study represents the possibility of significantly and proactively responding to future challenges in healthcare. The use of automated approaches in evaluating comprehensive volumes of data poses a challenge of increasing importance in the clinical setting as well. In this 
area the German National Cohort Study can serve to establish the interaction from (semi-) automated analyses with manual review first in the scientific context. The situation is similar in quality management: Approaches such as automated image quality control within the German National Cohort Study are gaining importance in the area of clinical treatment. The use of evaluation strategies such as radiomics, for example, allows the development of new and improved image-based risk stratifications, which offer high potential for personalized medicine and prevention in the future [7]. However, this demands the cooperation and explicit involvement of many different scientists both domestically and internationally, far exceeding the scope of the experts already involved. Moreover, this is possible only with the support of known foundations and recognized specialist associations such as, for example, Deutschen Röntgengesellschaft [German X-Ray Association].

\section{Summary}

$\nabla$

Population-based imaging is an increasingly relevant radiological scientific field that will influence the course of clinical radiology in the future. The MRI study of the German National Cohort, which involves the examination of roughly 30000 participants using 3-Tesla whole-body MRI, constitutes a unique opportunity to gain key knowledge in the understanding of (subclinical) diseases and to achieve the development of an image-based risk stratification for personalized medicine. Radiomics is a relatively new approach in which image information, analogously to laboratory or genome data, is translated and compiled via traditional diagnostic information (qualitative findings) into quantitative, disease-relevant information. With the complex procedures established in the German National Cohort for quality assurance and data standardization, the study may provide a basis for the future developments within Radiology and allows domestic and international scientists access to a unique dataset that can facilitate better understanding of the widest array of pathological processes and the socioeconomic relevance thereof.

\section{Affiliations}

1 Department of Diagnostic and Interventional Radiology, University Hospital Heidelberg

2 Department of Clinical Radiology, Klinikum der Universität München, Campus Großhadern, München, Germany

Department of Diagnostic and Interventional Radiology, University Hospital Tübingen, Germany

4 MEVIS, Fraunhofer, Bremen, Germany

5 Department of Diagnostic and Interventional Radiology and Neuroradiology, Univ. Duisburg-Essen, Medical Faculty, Essen, Germany

6 Department of Diagnostic Radiology and Neuroradiology, Ernst-MoritzArndt-University, Greifswald, Germany

7 Community Medicine, Universitätsklinikum Greifswald, Germany

\section{Acknowledgement \\ $\nabla$}

The German National Cohort is funded by the German Ministry for Education and Research (BMBF), the Federal States, and the Helmholtz Association.

We would like to thank all members of the German National Cohort MRI Study Investigators including:

\section{MRI Study Site Augsburg}

Thomas Kroencke, Armin Seifarth, Fabian Bamberg, Wieland Sommer, Maximilian F. Reiser, Birgit Ertl-Wagner, Günter Lewentat, Alexandra Kragler, Alexandra Montag, Erich Wichmann, Jakob Linseisen

\section{MRI Study Site Mannheim/Heidelberg}

Robert C. Bertheau, Karin Halina Greiser, Tanja Höpker, Andreas Meyer Lindenberg, Rudolf Kaaks, Hans-Ulrich Kauczor, Christopher L. Schlett, Oyunbileg von Stackelberg, Sabine Weckbach

\section{MRI Study Site Berlin}

Thoralf Niendorf, Tobias Pischon, Jeanette Schulz-Menger

\section{MRI Study Site Essen}

Michael Forsting, Armin de Greiff, Karl-Heinz Jöckel, Susanne Ladd, Anton Quinston, Börge Schmidt

MRI Study Site New Brandenburg

Norbert Hosten, Stefanie Kau, Robin Bülow, Henry Völzke

Imaging core for coordination \& training in Munich

Fabian Bamberg, Thomas Hendel, Julia Mischner, Michele

Picciolo, Maximilian F. Reiser, Sonja Selder

Imaging core for data management in Bremen

Matthias Günther, Jochen Hirsch, Alexander Köhn, Andreas Thomsen

Imaging core for incidental findings in Heidelberg

Robert C. Bertheau, Buket Selmi, Christopher L. Schlett, Migle Sumkauskaite, Sabine Weckbach, Hans-Ulrich Kauczor, Oyunbileg von Stackelberg

Imaging core for quality management in Greifswald Robin Bülow, Norbert Hosten, Stefanie Kau, Henry Völzke

Scientific Research Group: MSK Imaging

Marc-André Weber (Chair), Patrick Asbach, Felix Eckstein, Klaus-Peter Günther, Katrin Hegenscheid, Mike Notohamiprodjo, Frank Pessler, Frank Roemer, Armin Seifarth, Christopher L. Schlett, Gerwin Schmidt, Carsten Oliver Schmidt, Sabine Weckbach

\section{Scientific Research Group: Body Imaging}

Hans-Ulrich Kauczor (Chair), Thomas Kröncke, Jong Hee Hwang, Jens-Peter Kühn, Ralf Puls, Michael Roden, Christopher L. Schlett, Daniel Theisen, Frank Wacker

Scientific Research Group: Neuro Imaging

Michael Forsting (Chair), Svenja Caspers (Chair), Alfons Schnitzler, Katrin Amunts, Klaus Berger, Susanne Ladd, Arno Villringer, Matthias Günther

\section{Scientific Research Group: Cardiovascular Imaging}

Fabian Bamberg (Chair), Jeanette Schulz-Menger (Vorsitzende), Marc Dewey, Marcus Dörr, Tobias Saam, Christopher L. Schlett, Henning Steen, Daniel Theisen

\section{Central Data management}

Daniel Kraft, Rudolf Kaaks, Stefan Ostrzinski, Wolfgang Hoffmann

\section{MR External Advisory Board}

Udo Hoffmann (Chair), Jeff Carr, Christopher J O’Donnell, Arfan Ikram, Christopher Kramer, Gabriel Krestin, Steffen Petersen 


\section{Scientific collaborations}

Siemens Healthcare (Erlangen, Germany); Joachim Graessner, Regina Hunger, Bernd Ohnesorge, Helder M. Reboredo

\section{References}

1 [Anonym]. The German National Cohort: aims, study design and organization. Eur J Epidemiol 2014; 29: 371 - 382

2 Bamberg F, Kauczor HU, Weckbach S et al. Whole-Body MR Imaging in the German National Cohort: Rationale, Design, and Technical Background. Radiology 2015; 277: 206 - 220

3 Srivastava S, Gopal-Srivastava R. Biomarkers in cancer screening: a public health perspective. J Nutr 2002; 132: 2471S - 2475S

4 Elmore JG, Armstrong $K$, Lehman CD et al. Screening for breast cancer. JAMA 2005; 293: 1245 - 1256

5 Kumar V, Gu Y, Basu S et al. Radiomics: the process and the challenges. Magn Reson Imaging 2012; 30: 1234 - 1248

6 Kwong RY, Farzaneh-Far A. Measuring myocardial scar by CMR. JACC Cardiovasc Imaging 2011; 4: 157-160

7 [Anonym]. Medical imaging in personalised medicine: a white paper of the research committee of the European Society of Radiology (ESR). Insights Imaging 2015; 6: $141-155$

8 [Anonym]. ESR Position Paper on Imaging Biobanks. Insights Imaging 2015; 6: 403-410

9 Ahrens W, Jockel KH. The benefit of large-scale cohort studies for health research: the example of the German National Cohort. Bundesgesundheitsblatt Gesundheitsforschung Gesundheitsschutz 2015; 58: 813 821

10 Lambin P, Rios-Velazquez E, Leijenaar $R$ et al. Radiomics: extracting more information from medical images using advanced feature analysis. European journal of cancer 2012; 48: 441 - 446

11 Aerts HJ, Velazquez ER, Leijenaar RT et al. Decoding tumour phenotype by noninvasive imaging using a quantitative radiomics approach. Nat Commun 2014; 5: 4006

12 Chicklore S, Goh V, Siddique M et al. Quantifying tumour heterogeneity in 18F-FDG PET/CT imaging by texture analysis. European journal of nuclear medicine and molecular imaging 2013; 40: 133-140

13 Khalvati F, Wong A, Haider MA. Automated prostate cancer detection via comprehensive multi-parametric magnetic resonance imaging texture feature models. BMC medical imaging 2015; 15: 27

14 Parmar C, Rios Velazquez E, Leijenaar R et al. Robust Radiomics feature quantification using semiautomatic volumetric segmentation. PloS one 2014; 9: e102107

15 Velazquez ER, Parmar C, Jermoumi M et al. Volumetric CT-based segmentation of NSCLC using 3D-Slicer. Scientific reports 2013; 3: 3529

16 Blaschke T, Hay GJ, Kelly M et al. Geographic Object-Based Image Analysis - Towards a new paradigm. ISPRS J Photogramm Remote Sens 2014; 87: 180 - 191

17 Parmar C, Grossmann P, Bussink J et al. Machine Learning methods for Quantitative Radiomic Biomarkers. Scientific reports 2015; 5: 13087

18 Volzke H, Schmidt CO, Hegenscheid K et al. Population imaging as valuable tool for personalized medicine. Clin Pharmacol Ther 2012; 92 $422-424$

19 Raiko JR, Magnussen CG, Kahonen $M$ et al. Tracking of noninvasive ultrasound measurements of subclinical atherosclerosis in adulthood: findings from the Cardiovascular Risk in Young Finns Study. Ultrasound Med Biol 2010; 36: 1237-1244

20 Wolff B, Volzke H, Ludemann J et al. Association between high serum ferritin levels and carotid atherosclerosis in the study of health in Pomerania (SHIP). Stroke 2004; 35: 453-457

21 Bauer M, Hoffmann B, Mohlenkamp S et al. Distribution of carotid intima media thickness in men and women with and without coronary heart disease. Cross-sectional data of the Heinz Nixdorf Recall Study. Herz 2013; 38: $501-508$

22 Hofman A, van Duijn CM, Franco OH et al. The Rotterdam Study: 2012 objectives and design update. Eur J Epidemiol 2011; 26: 657-686

23 Stuckey DJ, Carr CA, Tyler DJ et al. Cine-MRI versus two-dimensional echocardiography to measure in vivo left ventricular function in rat heart. NMR Biomed 2008; 21: 765-772
24 Peters SA, Grobbee DE, Bots ML. Carotid intima-media thickness: a suitable alternative for cardiovascular risk as outcome? Eur J Cardiovasc Prev Rehabil 2011; 18: 167-174

25 [Anonym]. Vascular factors and risk of dementia: design of the ThreeCity Study and baseline characteristics of the study population. Neuroepidemiology 2003; 22: 316-325

26 Ikram MA, van der Lugt A, Niessen WJ et al. The Rotterdam Scan Study: design update 2016 and main findings. Eur J Epidemiol 2015; 30: $1299-1315$

27 Bergstrom G, Berglund G, Blomberg A et al. The Swedish CArdioPulmonary BioImage Study: objectives and design. J Intern Med 2015; 278 : $645-659$

28 Meijs MF, Bots ML, Vonken EJ et al. Rationale and design of the SMART Heart study: A prediction model for left ventricular hypertrophy in hypertension. Neth Heart J 2007; 15: 295-298

29 Hetterich $H$, Bayerl C, Peters A et al. Feasibility of a three-step magnetic resonance imaging approach for the assessment of hepatic steatosis in an asymptomatic study population. Eur Radiol 2015; DOI: 10.1007/ s00330-015-3966-y

30 Schlemmer HP, Schafer J, Pfannenberg $C$ et al. Fast whole-body assessment of metastatic disease using a novel magnetic resonance imaging system: initial experiences. Invest Radiol 2005; 40: 64-71

31 Hegenscheid $K$, Kuhn JP, Volzke $H$ et al. Whole-body magnetic resonance imaging of healthy volunteers: pilot study results from the population-based SHIP study. Fortschr Röntgenstr 2009; 181: 748 - 759

32 Petersen SE, Matthews PM, Bamberg F et al. Imaging in population science: cardiovascular magnetic resonance in 100000 participants of UK Biobank - rationale, challenges and approaches. Journal of cardiovascular magnetic resonance: official journal of the Society for Cardiovascular Magnetic Resonance 2013; 15: 46

33 Schlett CL, Hendel T, Hirsch J et al. Quantitative, Organ-Specific Interscanner and Intrascanner Variability for $3 \mathrm{~T}$ Whole-Body Magnetic Resonance Imaging in a Multicenter, Multivendor Study. Invest Radiol 2016; 51: 255-265

34 Erbel R, Eisele L, Moebus S et al. The Heinz Nixdorf Recall study. Bundesgesundheitsblatt Gesundheitsforschung Gesundheitsschutz 2012; 55 $809-815$

35 Harris TB, Launer LJ, Eiriksdottir G et al. Age, Gene/Environment Susceptibility-Reykjavik Study: multidisciplinary applied phenomics. Am J Epidemiol 2007; 165: 1076-1087

36 Becker N, Motsch E, Gross ML et al. Randomized study on early detection of lung cancer with MSCT in Germany: study design and results of the first screening round. J Cancer Res Clin Oncol 2012; 138 : $1475-1486$

37 Ru Zhao Y, Xie X, de Koning HJ et al. NELSON lung cancer screening study. Cancer Imaging 2011; 11: S79-S84

38 Engelke K, Libanati C, Liu Y et al. Quantitative computed tomography (QCT) of the forearm using general purpose spiral whole-body CT scanners: accuracy, precision and comparison with dual-energy X-ray absorptiometry (DXA). Bone 2009; 45: 110-118

39 Emaus $N$, Wilsgaard T, Ahmed LA. Impacts of body mass index, physical activity, and smoking on femoral bone loss: the Tromso study. J Bone Miner Res 2014; 29: 2080-2089

40 Rothney MP, Brychta RJ, Schaefer EV et al. Body composition measured by dual-energy X-ray absorptiometry half-body scans in obese adults. Obesity (Silver Spring) 2009; 17: 1281-1286

41 Harvey NC, Matthews P, Collins R et al. Osteoporosis epidemiology in UK Biobank: a unique opportunity for international researchers. Osteoporos Int 2013; 24: $2903-2905$

42 Hegenscheid $K$, Seipel $R$, Schmidt CO et al. Potentially relevant incidental findings on research whole-body MRI in the general adult population: frequencies and management. Eur Radiol 2013; 23: 816-826

43 Schmidt CO, Hegenscheid K, Erdmann Pet al. Psychosocial consequences and severity of disclosed incidental findings from whole-body MRI in a general population study. Eur Radiol 2013; 23: 1343-1351

44 Flanders $A E$. Medical image and data sharing: are we there yet? Radiographics 2009; 29: 1247-1251 